\title{
An Investigation into the Use of ERP Systems in the Public Sector
}

\author{
Maria Céu Gaspar Alves ${ }^{1}$ and Sergio Ivo Amaral Matos ${ }^{2}$ \\ ${ }^{1}$ University of Beira Interior/NECE, Covilhã, Portugal \\ ${ }^{2}$ University of Minho, Braga, Portugal
}

\begin{abstract}
During recent years, public organizations have invested considerable resources in the implementation of Enterprise Resource Planning (ERP) systems, even using solutions initially targeted for manufacturing companies. The interest generated by the ERP phenomenon in the public-sector still growing and the particularities of this sector make specific studies necessary. Just a few empirical studies have looked at public-sector motivations for ERP implementation and it appears from previous studies that organizational conditions of public and private organizations are different. This suggests that the reasons to implement ERP system may also differ. Consequently, the aim of this paper is to get an insight into how public organizations approach ERP implementation.
\end{abstract}

Based on a survey of public organizations we try to identified and characterize the motivations that lead to the adoption of ERP systems, and to identify and understand modules adoption in the public-sector. Overall, our findings reveal that the need to increase the demand for realtime information, to obtain information for decision-making and the integration of applications appear as main reasons to implement an ERP system. The study also reveals that Financial Accounting and Material Management modules are the most implemented.

This paper reinforces the need for more research focused on public sector organizations. Since literature on ERP implementation on public-sector is relatively sparse, our paper helps to narrow this knowledge gap.

Keywords: ERP implementation, Public-Sector; Survey; Portugal

\section{Introduction}

As far as we know, public organizations were not in the initial target zone of many ERP vendors, which instead developed product for manufacturing companies.

However, ERP systems are increasingly being implemented in the public sector. And, despite the downturn in the global economy, there has been a worldwide trend of ERP implementations in the public-sector (Thomas and Jajodia, 2004). The market was $\$ 16.67$ billion in 2005 and is forecasted to be over $\$ 21$ billion in 2010 , according to a new ARC Advisory Group study (ARC, 2006). Implementing an ERP system in the public-sector is a difficult task and not much research was done in this area. Therefore, the aim of this paper is to examine the adoption process of ERP systems by Portuguese public organizations. Which modules have been implemented and why? Which reasons for adopting an ERP system?

In public organizations adoption of new information technology innovations are affected by governmental, political and legal factors (Griffin and Dempsey, 2008; 
Botta-Genoulaz and Millet, 2006). In order to identify and discuss differences between public and private organizations in the context of ERP implementation, Wagner and Antonucci (2009) present an examination of the literature. In the comparison of ERP implementations between public and private-sectors, culture has been identified as a major difference (Thomas and Jajodia, 2004). In contrast to private firms that implement information technology applications as competitive weapons, public agencies must often share their applications and competencies with other agencies (Uwizeyemungu and Raymond, 2005).

The complex political system and fragmented power system intensifies the challenge in obtaining top management commitment (Gulledge and Sommer, 2003; Thomas and Jajodia, 2004). In the publicsector, top level managers, i.e. political appointees are less inclined toward the development of new information technology investments than middle managers, i.e. career managers (Uwizeyemungu and Raymond, 2005).

Information Technology investment planning in the public-sector must often bow to political pressure and is thus mostly oriented in the short term (Uwizeyemungu and Raymond, 2005).

"Government organizations, due to their social obligations, higher legislative and public accountability, and unique culture face many specific challenges in the transition to enterprise system" (BottaGenoulaz and Millet, 2006:211). The organizational structure of several public organizations tends to be more complex and the organizational complexity (fragmented departments) affects the ability to identify appropriate process owners (Wagner and Antonucci, 2009).

Usually, ERP implementations in public organization are done by large team. The team composition is quite different and bigger than in private-sector, in order to accommodate representation from the many departments and divisions. In public organization resources are allocated by budgetary processes rather than by market mechanisms as in the private-sector (Uwizeyemungu and Raymond, 2005). Consequently, budgeting and allocations are more difficult than in the private-sector (Thomas and Jajodia, 2004; Wagner and Antonucci, 2009).

Finally, it is difficult to identify the "best business practices" and the "customer" for the public arena (Wagner and Antonucci, 2009). But, to survive, public organizations must be viewed as service providers that meet the needs of their customers.

An ERP system is an integrated software package composed by a set of standard functional modules which can be adapted to the specific needs of each organization. According to Davenport (1998) "an enterprise system enables a company to integrate the data used throughout its entire organization" (p.122). Regarding the modules of the ERP system implemented, the literature review highlights the predominance of the modules for financial accounting and management (Spathis and Constantinides, 2004; Spathis, 2006; Ribeiro, 2008). Additionally, there are modules of costs and stock. It should be noted that organizations that have implemented ERP systems had as their main concern the integration of their accounting processes (Spathis and Constantinides, 2004; Spathis, 2006).

The interest generated by ERP implementation in the public-sector and the particularities of this sector make specific studies of ERP in public organizations necessary (Uwizeyemungu and Raymond, 2005). According to Youngberg et al (2009), in their technology acceptance research Venkatesh et al (2003) suggest focusing future investigations on public organizations to expand the research scope to this specialized business segment.

It appears from previous studies that organizational conditions of public and private organizations are different. This suggests that the reasons to implement ERP system may also differ. Since literature on ERP implementation on public-sector is 
relatively sparse, our paper helps to narrow this knowledge gap.

\section{Research Method and Methodology}

As in Griffin and Dempsey (2008), after reviewing the literature available, a gap which has not been adequately covered was recognized. Much has been written on successful ERP implementation on the private sector but very little has been done on the public sector. Consequently, this paper contributes to narrow this knowledge gap.

A field survey was conducted in this study to collect data. The sampling frame of this research was prepared following consultation with the ERP major providers (Jacobson et al., 2007) in Portugal " $S A P$ Portugal" who presented us a list of successful clients, available in the SAP website (www.sap.pt). Thus, it was defined a population of nine public organizations that have successfully implemented the ERP system from SAP.
The survey instrument (questionnaire) was developed by identifying appropriate means of measurement from previous literature. Eight of the nine public organizations completed the questionnaire.

\section{Results and Discussion}

According to Botta-Genoulaz and Millet (2006) "Government organizations are increasing the adoption of ERP systems for various benefits such as integrated realtime information, better administration, and result-based management"(p.211). When asked about the main reasons for implementing the ERP system, almost all the respondents answered: the integration of applications, the increased demand for real-time information, the integration of information and the Information generation for decision-making. The other reasons that lead public organizations to implement the ERP system can be observed in table1.

Table 1 - Reasons for ERP Implementation in Portuguese Public Organizations

\begin{tabular}{lcc}
\hline Reasons & Frequency & $\mathbf{\%}$ \\
Integration of applications & 8 & 100 \\
Increased demand for real-time information & 6 & 75 \\
Integration of information & 6 & 75 \\
Information generation for decision-making & 6 & 75 \\
Business process re-engineering (BPR) & 3 & 38 \\
Introduction of EURO & 3 & 38 \\
Competition & 2 & 25 \\
Others situations & 2 & 25 \\
Costs reduction & 1 & 13 \\
Y2K problems (consequences of new millennium on & 13 \\
data format) & & 13 \\
\hline
\end{tabular}

The findings corroborate the results of studies conducted in several countries in the public-sector (Uwizeyemungu and Raymond 2005; Raymond et al., 2005; Singla 2008) but also in the private-sector (Scapens and Jazayeri, 2003; Spathis, 2006 e Sayed, 2006).

In the organizations surveyed it was found that most of the modules implemented were: the Financial Accounting module (8 organizations); the materials management module (6 organizations), and the
Controlling module (6 organizations). This result corroborates those from other studies (Spathis and Constantinides, 2004; Spathis, 2006; Ribeiro, 2008), according to which in the organizations that have implemented ERP system; the financial accounting and management module are dominating. Thus we can conclude that organizations began by implementing the modules of accounting, which shows an initial concern on their part to integrate their accounting processes and thus the 
data collected allow us to confirm this hypothesis.

\section{Conclusions and limitations}

In this study, the main reasons that lead a public organization to implement an ERP system were analyzed, and we asked about the most implemented modules with the ERP system.

The results suggest as the main motivators for the implementation of ERP system: the search for systems integration, the increasing demand for real-time information, the demand for integration of information systems, the need to generate information for decision- making and the increase of competitiveness in markets. These results are similar to the literature review.

Moreover, it was found that in the surveyed organizations the data collected indicate that the organizations that have implemented ERP systems began to implement the modules of accounting. These results show a concern by public organizations to integrate their processes, starting with the area of accounting.

Like other studies, our analysis is limited by both data and empirical specifications concerns. Only eight organizations were investigated, other organizations with successfully implemented ERP systems may have been overlooked.

\section{Acknowledgement}

The authors would like to thanks the Portuguese Foundation for Science and Technology and the Research Unit NECE / UBI for providing financial support for this research.

\section{References}

ARC - Advisory Group, Enterprise Resource Planning (ERP) (2006). Enterprise Resource Planning Worldwide Outlook Five year Market Analysis and Technology Forecast Through 2011, (accessed on 17/03/2010). Available:

http://www.arcweb.com/res/erp.
Botta-Genoulaz, V. \& Millet, P.-A. (2006). "An Investigation into the Use of ERP Systems in the Service Sector," International Journal of Production Economics, 99, pp. 202-221.

Davenport, T. (1998). "Putting the Enterprise into the Enterprise System," Harvard Business Review, July/Aug, pp. 121131.

Griffin, J. \& Dempsey, S. (2008). "The Implementation of a Computerised Integrated System in a Public Service Organization," International Journal of Business and Management, August, 149156.

Gulledge, T. \& Sommer, R. (2003). "Public Sector Enterprise Resource Planning," Industrial Management \& Data Systems, 103(7), 471-483.

Jacobson, S., Shepherd, J., D'Aquila, M. \& Carter, K. (2007). The ERP Market Sizing Report, 2006-2011, AMR Research, Boston MA.

Raymond, L., Uwizeyemungu, S. \& Bergeron, F. (2005). "ERP Adoption fo EGovernement: An Analysis of Motivations," Proceedings of the eGovernment Workshop '05 (eGOV05), September 13 2005, Brunel University, West London UB8 3PH, UK.

Ribeiro, P. (2009). "Estudo do Impacto de Sistemas Enterprise Resource Planning nas Empresas e na Contabilidade de Gestão: Evidência a Partir de um Estudo de Caso," Master Thesis, ISCTE Business School, Lisbon.

Sayed, H. (2006). "ERPs and Accountants' Expertise: The Construction of Relevance," Journal of Enterprise Information Management, 19(1), 83-96.

Scapens, R. \& Jazayeri, M. (2003). "ERP Systems and Management Accounting Change: Opportunities or Impacts? A Research Note," European Accounting Review, 12(1), 201-233.

Singla, A. R. (2008). "Impact of ERP Systems on Small and Mid Sized Public 
Sector Enterprises," Journal of Theoretical and Applied Information Technology. 4(2), 119-31.

Spathis, C. (2006). "Enterprise Systems Implementation and Accounting Benefits," Journal of Enterprise Information Management, 9(1), 67-82.

Spathis, C. \& Constantinides, S. (2004). 'Enterprise Resource Planning Systems' Impact on Accounting Processes," Business Process Management Journal, 10(2), 234247.

Thomas, G. \& Jajodia, S. (2004). "Commercial off-the-Shelf Enterprise Resources Planning Software Implementations in the Public Sector: Practical Approaches for Improving Project Success," The Journal of Government Financial Management, 53(2), 12-18.

Uwizeyemungu S. \& Raymond L. (2005). "Motivations for ERP Adoption in the public sector; An analysis from "success stories," Proceedings of the Annual Conference of the Administrative Science Association of Canada Information Systems Division. Toronto. Ontário. Pp.220-231.

Venkatesh, V., Morris M., Davis, G. \& Davis F. (2003). "User Acceptance of Information Technology: Toward a unified View," MIS Quarterly, 27(3), 425-478.

Wagner, W. \& Antonucci, Y. (2009). "The Imagine PA Project: The First Large-Scale, Public Sector ERP Implementation," Information Systems Management, 26(3), $275-284$.

Youngberg, E., Olsen, D. \& Hauser K. (2009). "Determinants of Professionally Autonomous End User Acceptance in an Enterprise Resource Planning," International Journal of information Management, 29, 138-144. 